\title{
Adiponectin complexes composition in Japanese- Brazilians regarding their glucose tolerance status
}

\author{
Felipe Crispim, Marcio F Vendramini, the Japanese-Brazilian Diabetes Study Group and Regina S Moisés*
}

\begin{abstract}
Background: Adiponectin circulates in different multimer complexes comprised of low molecular weight trimeric form (LMW), hexamer of middle molecular weight (MMW) and high molecular weight multimers (HMW). In Japanese-Brazilians, a population with high prevalence of glucose metabolism disturbances, we examined the associations of total adiponectin and its multimers with diabetes mellitus.

Methods: Two study groups were examined: 26 patients with diabetes mellitus (DM,14 women and 12 men, aged $55.3 \pm 8.6$ years) and 27 age-matched control subjects with normal glucose tolerance (NGT,12 women and 15 men, aged $54.0 \pm 9.2$ years)

Results: We found no significant differences in total [NGT: $6.90 \mathrm{ug} / \mathrm{ml}$ (4.38-13.43); DM: $5.38 \mathrm{ug} / \mathrm{ml}$ (3.76-8.56), $p=0.35$ ], MMW [NGT:2.34 ug/ml (1.38-3.25); DM: $1.80 \mathrm{ug} / \mathrm{ml}$ (1.18-2.84), $p=0.48$ ] or LMW adiponectin [NGT: $2.07 \mathrm{ug} / \mathrm{ml}$ (1.45-3.48), DM: $2.93 \mathrm{ug} / \mathrm{ml}$ (1.78-3.99), $\mathrm{p}=0.32$ ] between groups. In contrast, HMW adiponectin levels were significantly lower in patients with DM [TGN: $2.39 \mathrm{ug} / \mathrm{ml}(1.20-4.75) ; \mathrm{DM}: 1.04 \mathrm{ug} / \mathrm{ml}(0.42-1.60), \mathrm{p}=0.001]$. A logistic regression analysis was done to identify independent associations with diabetes mellitus. The results showed that HOMA-IR and HMW adiponectin in women were independently associated with diabetes mellitus.

Conclusion: The current investigation demonstrates that in Japanese-Brazilians HMW adiponectin is selectively reduced in individuals with type 2 diabetes, while no differences were found in MMW and LMW adiponectin isoforms.
\end{abstract}

Keywords: Adiponectin, HMW adiponectin, Japanese-Brazilians

\section{Background}

Adiponectin, a peptide hormone predominantly expressed and secreted by adipocytes, has been recognized as an important regulator of insulin sensitivity [1-3]. It is present in the circulation of healthy individuals at high concentration, account for approximately $0.01 \%$ of total plasma protein. Hypoadiponectinemia is seen in states of insulin resistance such as type 2 diabetes, obesity and metabolic syndrome [4-6]. Adiponectin circulates in different multimer complexes comprised of low molecular weight trimeric form (LMW), hexamer of middle molecular weight (MMW) and high molecular weight multimers (HMW) [7]. Possibly these complexes have different functions and there are evidences indicating that HMW adiponectin might be the most active metabolically form. Indeed, previous studies

\footnotetext{
* Correspondence: rmoises@unifesp.br

Disciplina de Endocrinologia, Escola Paulista de Medicina, Universidade Federal de São Paulo, Rua Pedro de Toledo, 781, São Paulo, SP 04039-032, Brazil
}

showed that HMW adiponectin or the ratio HMW to total adiponectin correlates better with measures of insulin sensitivity [8,9] or glucose tolerance [10]. However, other studies failed to demonstrate the superiority of HMW adiponectin over total adiponectin in assessing insulin sensitivity. For example, in a Mexican population total adiponectin, HMW adiponectin and the ratio HMW/total adiponectin had similar utility for the identification of insulin resistance and metabolic disturbances [11]. Similarly, in a longitudinal study with Japanese-Americans lower both total and HMW adiponectin were independent risk factors for the development of metabolic syndrome [12].

Japanese-Brazilian is a population with high prevalence of glucose metabolism disturbances, being the prevalence of diabetes one of the highest worldwide [13]. In a previous study we showed that low plasma level of total adiponectin was an independent predictor for development of glucose intolerance in this population [14]. In

\section{() Biomed Central}


this study it was examined the associations of total adiponectin and its multimers with diabetes mellitus.

\section{Subjects and methods Subjects}

The study population was selected from the Japanese Brazilian Diabetes Study Group. Details on the selection and recruitment of this population were previously described [13]. For this study, we randomly selected a small subset of non-related subjects with suitable baseline serum specimens and normal glucose tolerance or diabetes mellitus matched for age and sex. Individuals with impaired fasting glucose, impaired glucose tolerance or severe kidney disease $\left(\right.$ eGFR $<30 \mathrm{~mL} / \mathrm{min} / 1.73 \mathrm{~m}^{2}$ ) were excluded. A subset of 53 individuals was selected: 26 patients with diabetes mellitus (DM,14 women and 12 men, aged $55.3 \pm 8.6$ years) and 27 control subjects with normal glucose tolerance (NGT,12 women and 15 men, aged 54.0 \pm 9.2 years). Individuals went through an interview with questionnaires regarding social aspects and medical history. Clinical examination was performed and included anthropometric (weight, height, waist circumference and hip circumference) and blood pressure measurements. Fasting blood samples for glucose, insulin, lipids and adiponectin were obtained. Morning medications were deferred until all procedures were done. A $75 \mathrm{~g}$ anhydrous glucose was administered to all subjects with fasting capillary glucose $<200 \mathrm{mg} / \mathrm{dL}$ screened by glucoseoxidase strips. After $2 \mathrm{~h}$ another blood sample was obtained for glucose measurements.

This study was approved by the Ethics Committee of the Federal University of São Paulo, and all participants gave their informed consent.

\section{Laboratory methods}

Plasma glucose was determined by the glucose-oxidase method. Cholesterol contents of lipoproteins fractions and triglycerides were measured enzymatically. Insulin was determined by a monoclonal antibody-based immunofluorimetric assay (PerkinElmer, Wallac Oy, Turku, Finland) that does not react with proinsulin. Insulin resistance was estimated by homeostasis model assessment (HOMA-IR) [15]. Estimated glomerular filtration rate (eGFR) was determined by the Modification of Diet in Renal Disease (MDRD) equation. Glucose tolerance status was based on WHO criteria [16]. Serum total adiponectin concentrations were measured by radio-immunoassay according to manufacter's instructions (Linco Research, St. Charles, MI, USA) in specimens that had been stored at $-20^{\circ} \mathrm{C}$. This assay utilizes ${ }^{125} \mathrm{I}$-labeled murine adiponectin and a multi-species adiponectin antiserum. Samples were diluted 1:500 in assay buffer prior to measurements. The assay has a sensitivity of $1 \mathrm{ng} / \mathrm{mL}$ with an intra- and inter- assay coefficients of variation of $1,8-6,2 \%$ and $6,9-9,3 \%$, respectively.

\section{SDS-PAGE and immunoblotting for determination of adiponetin multimers}

The relative amounts of adiponectin multimers were determined by Western blot analysis. Serum was diluted 10 -fold with deionized water and $5 \mathrm{uL}$ of this diluted serum plus $5 \mathrm{uL}$ of protein loading buffer was separated under non-reducing and non-heat-denaturating conditions on $4-12 \%$ polyacrylamide gel electrophoresis. SDSPAGE was performed according to standard Laemmli procedure. Following electrophoresis, the proteins were transferred to nitrocellulose membrane (Hybond ECL, Amersham Biosciences, Piscataway, NJ, USA) and incubated with blocking solution (5\% nonfat milk in Trisbuffered saline with $0.05 \%$ Tween 20) for $1 \mathrm{~h}$ at room temperature. The blocking solution was removed and replaced with the same solution containing 1:10,000 dilution of a mouse antihuman adiponectin monoclonal antibody (BD Bioscience, San Jose, CA, USA). The incubation was continued overnight at $4^{\circ} \mathrm{C}$. After being washed the nitrocellulose was incubated with horseradish peroxidaseconjugated goat anti-mouse immunoglobulins (Santa Cruz Biotechnology, Inc, Santa Cruz, CA, USA) with 1:5,000 dilution for $1 \mathrm{~h}$ at room temperature and washed thoroughly. Bands were detected by an enzymatic chemiluminescent Western blot detection system (SuperSignal West Pico Chemiluminescent Substrate, Thermo Fisher Scientific, Rockford, IL, USA) and quantified by densitometry analysis using the Image J software. Relative proportions of adiponectin multimers were calculated by dividing band density by total density in each lane. The absolute adiponetin multimer values were extrapolated by multiplying the relative proportions by the total adiponectin concentrations detected by RIA, assuming that all multimers are immunoreactive on the immunoblot.

\section{Statistical analysis}

Data with normal distribution, tested by KolmogorovSmirnov test, are expressed as mean \pm SD while variables nonnormally distributed are reported as median (interquartile range). Differences in continuous variables between groups were evaluated by unpaired Student's test or Mann-Whitney test. The relative proportions of adiponectin multimers between groups were compared by using the Holling T2 test. Univariate associations between variables were investigated by Spearman correlation analysis. Logistic regression model was used to identify independent associations with diabetes mellitus. Model fit was assessed using the Akaike Information Criterion. A P-value of $<0.05$ was considered statistically significant. 


\section{Results}

The main characteristics of the study population are shown in Table 1. Individuals with DM had significantly higher BMI, waist circumference, triglycerides and HOMA-IR than subjects with NGT. Figure 1 shows a representative immunoblot from serum of age and sex matched individuals with DM and NGT. Bands were found at $>300 \mathrm{kDa}$ representing HMW adiponectin, at $\sim 180 \mathrm{kDa}$ representing MMW adiponectin and at $\sim 70 \mathrm{kDa}$ representing LMW adiponectin. As displayed in Figure 2, no significant differences in total [NGT: $6.90 \mathrm{ug} / \mathrm{ml}$ (4.38-13.43); DM:

Table 1 Characteristics of the subjects with normal glucose tolerance (NGT) or diabetes mellitus (DM)

\begin{tabular}{|c|c|c|c|}
\hline & NGT $(n=27)$ & $\mathrm{DM}(n=26)$ & $P$ value \\
\hline Age (years) & $54.0 \pm 9.2$ & $55.3 \pm 8.6$ & $0.58^{\mathrm{a}}$ \\
\hline $\operatorname{BMI}\left(\mathrm{kg} / \mathrm{m}^{2}\right)$ & $23.4 \pm 2.4$ & $25.1 \pm 2.4$ & $0.015^{\mathrm{a}}$ \\
\hline $\begin{array}{l}\text { Waist circumference } \\
(\mathrm{cm})\end{array}$ & $79.4 \pm 6.5$ & $85.1 \pm 7.6$ & $0.005^{\mathrm{a}}$ \\
\hline Waist-hip ratio & $0.83 \pm 0.05$ & $0.88 \pm 0.07$ & $0.005^{\mathrm{a}}$ \\
\hline $\begin{array}{l}\text { Total cholesterol } \\
\text { (mg/dL) }\end{array}$ & $200.9 \pm 39.3$ & $209.7 \pm 33.4$ & $0.384^{\mathrm{a}}$ \\
\hline $\begin{array}{l}\text { HDL-Cholesterol } \\
\text { (mg/dL) }\end{array}$ & $48.8 \pm 14.1$ & $48.1 \pm 8.4$ & $0.809^{a}$ \\
\hline $\begin{array}{l}\text { LDL-cholesterol } \\
\text { (mg/dL) }\end{array}$ & $121.7 \pm 39.1$ & $126.4 \pm 33.3$ & $0.638^{\mathrm{a}}$ \\
\hline $\begin{array}{l}\text { Triglycerides } \\
(\mathrm{mg} / \mathrm{dL})\end{array}$ & $132.0(97.2-171.5)$ & $227.5(160.0-380.0)$ & $0.001^{b}$ \\
\hline $\begin{array}{l}\text { Fasting plasma } \\
\text { glucose }(\mathrm{mg} / \mathrm{dL})\end{array}$ & $104.0(100.2-107.7)$ & $134.5(127.0-170.0)$ & $<0.001^{b}$ \\
\hline $\begin{array}{l}\text { Fasting plasma } \\
\text { insulin ( } \mathrm{UU} / \mathrm{mL} \text { ) }\end{array}$ & $5.8 \pm 2.7$ & $9.4 \pm 3.3$ & $<0.001^{a}$ \\
\hline HOMA-IR & $1.39(0.96-1.75)$ & $3.01(2.63-3.83)$ & $<0.001^{b}$ \\
\hline $\mathrm{eGFR}\left(\mathrm{mL} / \mathrm{min} / 1.73 \mathrm{~m}^{2}\right)$ & $98.1 \pm 37.3$ & $97.8 \pm 32.8$ & $0.97^{\mathrm{a}}$ \\
\hline $\mathrm{HbA} 1 \mathrm{C}(\%)$ & - & $6.2(5.7-7.1)$ & - \\
\hline
\end{tabular}

Treatment for diabetes $(n)$

$\begin{array}{ccc}\text { SU } & - & 2 \\ \text { MTF } & - & 1 \\ \text { SU + MTF } & - & 1 \\ \text { SU + INS } & - & 1\end{array}$

Treatment for hypertension (n)

B- blocker
Diuretic
ACEi

B-blocker + diuretic

Treatment for dyslipidemia (n)

fibrate

$\begin{array}{ll}2 & - \\ 1 & - \\ 1 & - \\ 1 & -\end{array}$

Data are presented as mean $\pm S D$, median (interquartile range) or $n$. SU: sulfonylrea; MTF: metformin; INS: insulin; ACEi: angiotensin-converting enzyme inhibitor;

a t-test.

${ }^{\mathrm{b}}$ Mann-Whitney test.

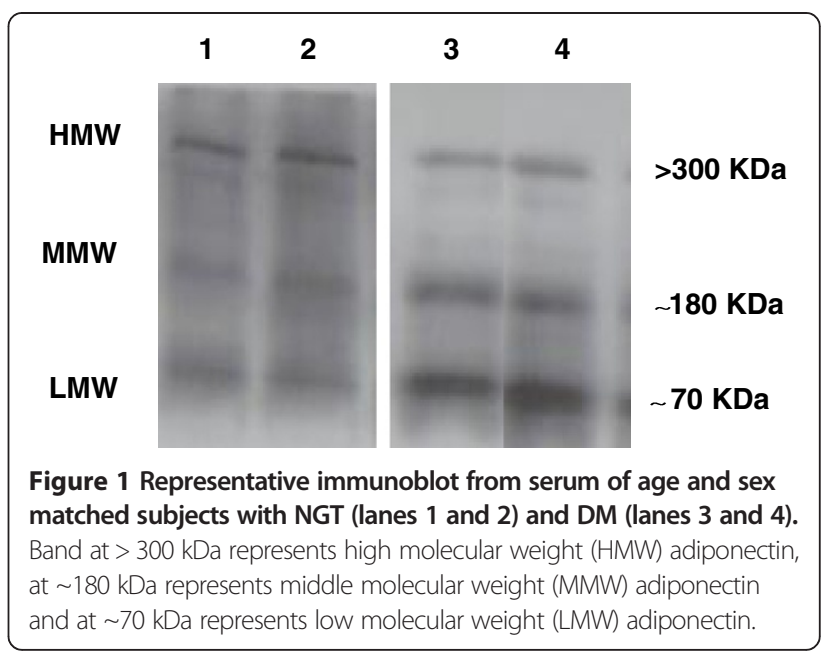

$5.38 \mathrm{ug} / \mathrm{ml}$ (3.76-8.56), $\mathrm{p}=0.35$ ], MMW [NGT:2.34 ug/ml (1.38-3.25); DM: $1.80 \mathrm{ug} / \mathrm{ml}(1.18-2.84), \mathrm{p}=0.48]$ or LMW adiponectin [NGT: $2.07 \mathrm{ug} / \mathrm{ml}$ (1.45-3.48), DM: $2.93 \mathrm{ug} / \mathrm{ml}$ (1.78-3.99), $\mathrm{p}=0.32$ ] were found between groups. In contrast, HMW adiponectin levels were significantly lower in patients with DM [NGT: $2.39 \mathrm{ug} / \mathrm{ml}$ (1.20-4.75); DM: $1.04 \mathrm{ug} / \mathrm{ml}(0.42-1.60), \mathrm{p}=0.001]$. The distribution of adiponectin isoforms in subjects with NGT and DM are shown in Figure 3. Lower proportions of HMW adiponectin and higher proportions of LMW adiponectin were observed in subjects with DM compared to NGT. No differences were found in proportions of MMW adiponectin.

Spearman rank correlation showed significant inverse correlations between BMI ( $\mathrm{rs}=-0.29, \mathrm{p}=0.034)$, HOMAIR ( $\mathrm{rs}=-0.36, \mathrm{p}=0.007$ ) and triglycerides ( $\mathrm{rs}=-0.22$, $\mathrm{p}=0.04$ ) with HMW adiponectin, MMW and LMW adiponectin were significantly associated with waist circumference $(\mathrm{rs}=-0.29, \mathrm{p}=0.03 ; \mathrm{rs}=-0.28, \mathrm{p}=0.03$ respectively). A trend for inverse correlation between BMI and total adiponectin ( $r s=-0.27, p=0.051$ ) was observed. No significant correlations were found for total adiponectin with HOMA-IR or triglycerides.

A logistic regression analysis was done to identify independent associations with diabetes mellitus. The covariates were waist/hip ratio, triglycerides levels, HOMA-IR, total and HMW adiponectin, including interaction with sex for total and HMW adiponectin. The results showed that HOMA-IR and HMW adiponectin in women were independently associated with diabetes mellitus (Table 2).

\section{Discussion}

In the present study, we measured total plasma adiponectin and its all three oligomeric isoforms in Japanese-Brazilians to investigate their relationship with diabetes mellitus. There are limited data concerning the role of these 


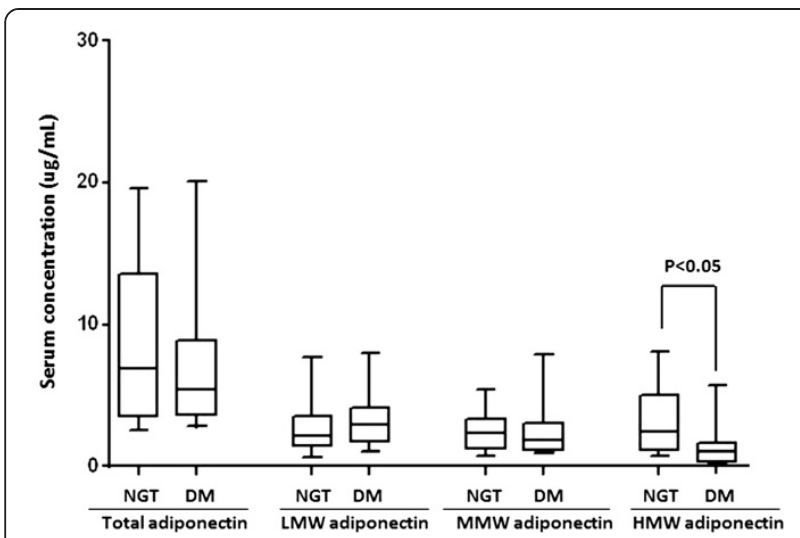

Figure 2 Serum concentrations of total, low molecular weight (LMW), middle molecular weight (MMW) and high molecular weight (HMW) adiponectin in individuals with normal glucose tolerance (NGT) or diabetes mellitus (DM). The box displays the median and interquartile range (25th-75th percentile) and the whiskers display the 10th and 90th values.

oligomers; most studies are mainly based on total adiponectin and HMW isoform.

Different methods have been employed for determination of adiponectin multimers such as velocity sedimentation coupled to quantitative Western-blot analysis, gel filtration chromatography and gel electrophoresis $[5,7,17,18]$. Pajvani et al. developed a method of velocity sedimentation analysis coupled to Western blot to separate and measure the adiponectin complexes [17]. This is a laborious technique and does not discriminate the lower molecular weight complexes. More recently, Schraw et al. validated a high-resolution gel filtration approach followed by fluorescent Western blotting that separated the three major adiponectin complexes in a reproducibly and accurate manner [19]. Waki et al. using a SDS-PAGE under non-reducing and non-heat-denaturing conditions clearly separated the adiponectin multimers in to three species and reported that this analysis was superior to the gel filtration in terms of resolving power [7]. In this study, it was employed SDS-PAGE under non-reducing and non-heat-denaturing conditions to detect the isoforms. In
Table 2 Odds ratio (OR) and 95\% confidence interval (CI) for diabetes mellitus according to biological variables

\begin{tabular}{ccc}
\hline & OR & $\mathbf{9 5 \% ~ C l}$ \\
\hline HMW adiponectin in women (for each 1\%) & 0.75 & $0.58-0.95$ \\
HMW adiponectin in men (for each 1\%) & 1.08 & $0.95-1.23$ \\
HOMA-IR (for each 0.1 unit) & 1.53 & $1.12-2.09$ \\
\hline
\end{tabular}

our hands, this procedure permitted a clear separation of the three bands.

In previous studies we showed that in JapaneseBrazilians, low plasma level of total adiponectin is an independent predictor of glucose intolerance and subjects with type 2 diabetes compared with normal glucose tolerant subjects have reduced levels of total adiponectin $[14,20]$. Here, in a small subset of this population, it was found that HMW adiponectin is selectively reduced in individuals with type 2 diabetes. As a consequence of a drop in HMW, an increase in the percentage of LMW was observed in individuals with DM compared to NGT. A correlation between insulin sensitivity, evaluated by HOMA-IR, and HMW adiponectin was observed. These findings support the role of HMW adiponectin as the major isoform mediating its insulin-sensitizing effects. Furthermore, in women, an increase of HWW adiponectin in percent has a significant decreased risk of diabetes mellitus. This is in agreement with previous studies showing that decreased HMW adiponectin is a better marker than total adiponectin for assessing the risk of type 2 diabetes $[8,21,22]$. However, other data do not support the superiority of HMW adiponectin in assessing parameters of insulin resistance [23] or risk of type 2 diabetes [24].

MMW and LMW adiponectin isoforms have not been extensively studied, as a result little is known regarding their distribution. In the present study no differences were found in MMW or LMW adiponectin between groups. Schober et al., using ELISA to measure the three isoforms, found that MMW and LMW adiponectin were reduced in the serum of type 2 diabetic patients when compared to normal weight controls [25]. However, Basu et al. using velocity sedimentation/gel filtration chromatography

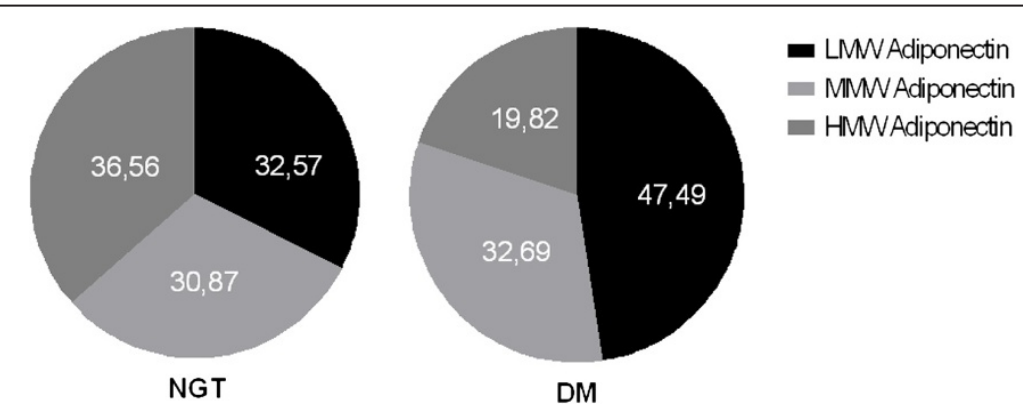

Figure 3 Percentual distribution of low molecular weight (LMW), middle molecular weight (MMW) and high molecular weight (HMW) adiponectin in individuals with normal glucose tolerance (NGT) or diabetes mellitus (DM). 
and Lara Castro et al. using immunoblot to separate HMW form from the remaining adiponectin isoforms found that the concentration of LMW fractions (hexameric and trimeric forms) did not differ in the diabetic and nondiabetic subjects $[8,26]$. These discrepancies may be explained by different methods for determination of adiponectin multimers or by ethnic differences.

\section{Conclusions}

The current investigation demonstrates that in JapaneseBrazilians HMW adiponectin is selectively reduced in individuals with type 2 diabetes, while no differences were found in MMW and LMW adiponectin isoforms.

\section{Abbreviations}

LMW: Low molecular weight; MMW: Middle molecular weight; HMW: High molecular weight; DM: Diabetes Mellitus; NGT: Normal glucose tolerance; HOMA-IR: Homeostatic model assessment-insulin resistance; BMI: Body mass index; HDL: High density lipoprotein; LDL: Low density lipoprotein;

ELISA: Enzyme-linked immunosorbent assay.

\section{Competing interests}

The authors declare that they have no competing interests.

\section{Authors' contributions}

FC: performed the experiments, analyzed the data and wrote the manuscript; MFV: participated in the design of the study and helped to draft the manuscript; RSM: conceived and designed the experiments, analyzed the data and wrote the manuscript. All authors read and approved the final manuscript.

\section{Acknowledgements}

Members of the Japanese-Brazilian Diabetes Study (JBDS) Group. Amelia T Hirai, Helena Harima, Katsumi Osiro, Mario Kikuchi, Suely GA Gimeno (Department of Preventive Medicine, Federal University of São Paulo, SP); Laercio J Franco (Department of Social Medicine, Medical School of Ribeirão Preto, University of São Paulo, SP), Luiza K Matsumura, Regina S Moisés (Endocrinology Division, Department of Internal Medicine, Universidade Federal de São Paulo, SP), Marly A Cardoso, Sandra RG Ferreira (Department of Nutrition, School of Public Health, University of São Paulo, SP) Newton de Barros Jr (Department of Surgery, Federal University of São Paulo, SP), Nilce Tomita (Bauru Faculty of Odontology, University of São Paulo, SP), Katsunori Wakisaka (Japanese-Brazilian Study Center, SP); Rita Chaim (Faculty of Nutrition, Sagrado Coração de Jesus University, Bauru, SP).

Received: 23 November 2012 Accepted: 1 April 2013

Published: 9 April 2013

\section{References}

1. Tschritter O, Fritsche A, Thamer C, Haap M, Shirkavand F, Rahe S, Staiger H, Maerker E, Haring H, Stumvoll M: Plasma adiponectin concentrations predict insulin sensitivity of both glucose and lipid metabolism. Diabetes 2003, 52(2):239-243

2. Abbasi F, Chu JW, Lamendola C, McLaughlin T, Hayden J, Reaven GM, Reaven PD: Discrimination between obesity and insulin resistance in the relationship with adiponectin. Diabetes 2004, 53(3):585-590.

3. Yamamoto Y, Hirose H, Saito I, Nishikai K, Saruta T: Adiponectin, an adipocyte-derived protein, predicts future insulin-resistance: two-year follow-up study in Japanese population. J Clin Endocrinol Metab 2004, 89:87-90.

4. Weyer C, Funahashi T, Tanaka S, Hotta K, Matsuzawa Y, Pratley RE, Tataranni PA: Hypoadiponectinemia in obesity and type 2 diabetes: close association with insulin resistance and hyperinsulinemia. J Clin Endocrinol Metab 2001, 86:1930-1935.

5. Arita Y, Kihara S, Ouchi N, Takahashi M, Maeda K, Miyagawa J, Hotta K, Shimomura I, Nakamura T, Miyaoka K, Kuriyama H, Nishida M, Yamashita S, Okubo K, Matsubara K, Muraguchi M, Ohmoto Y, Funahashi T, Matsuzawa Y:
Paradoxical decrease of an adipose-specific protein, adiponectin, in obesity. Biochem Biophys Res Commun 1999, 257(1):79-83.

6. Matsushita K, Yatsuya H, Tamakoshi K, Wada K, Otsuka R, Takefuji S, Sugiura K, Kondo T, Murohara T, Toyoshima H: Comparison of circulating adiponectin and proinflammatory markers regarding their association with metabolic syndrome in Japanese men. Arterioscler Thromb Vasc Biol 2006, 26(4):871-876.

7. Waki H, Yamauchi T, Kamon J, Ito Y, Uchida S, Kita S, Hara K, Hada Y, Vasseur F, Froguel P, Kimura S, Nagai R, Kadowaki T: Impaired multimerization of human adiponectin mutants associated with diabetes: molecular structure and multimer formation of adiponectin. J Biol Chem 2003, 278:40352-40363.

8. Lara-Castro C, Luo N, Wallace P, Klein RL, Garvey WT: Adiponectin multimeric complexes and the metabolic syndrome trait cluster. Diabetes 2006, 55:249-259

9. Pajvani UB, Hawkins M, Combs TP, Rajala MW, Doebber T, Berger JP, Wagner JA, Wu M, Knopps A, Xiang AH, Utzschneider KM, Kahn SE, Olefsky JM, Buchanan TA, Scherer PE: Complex distribution, not absolute amount of adiponectin, correlates with thiazolidinedione-mediated improvement in insulin sensitivity. J Biol Chem 2004, 279:12152-12162.

10. Fisher FM, Trujillo ME, Hanif W, Barnett AH, McTernan PG, Scherer PE, Kumar $\mathrm{S}$ : Serum high molecular weight complex of adiponectin correlates better with glucose tolerance than total serum adiponectin in IndoAsian males. Diabetologia 2005, 48:1084-1087.

11. Almeda-Valdes P, Cuevas-Ramos D, Mehta R, Gomez-Perez FJ, Cruz-Bautista I, Arellano-Campos O, Navarrete-Lopez M, Aguilar-Salinas CA: Total and high molecular weight adiponectin have similar utility for the identification of insulin resistance. Cardiovasc Diabetol 2010, 23:9-26.

12. Nakashima R, Yamane K, Kamei N, Nakanishi S, Kohno N: Low serum levels of total and high-molecular-weight adiponectin predict the development of metabolic syndrome in Japanese-Americans. J Endocrinol Invest 2011, 34(8):615-619.

13. Gimeno SGA, Ferreira SRG, Franco LJ, Hirai AT, Matsumura L, Moisés RS: Prevalence and 7-year incidence of type II diabetes mellitus in a Japanese-Brazilian population: an alarming public health problem. Diabetologia 2002, 45:1635-1638

14. Vendramini MF, Ferreira SRG, Gimeno SGA, Kasamatsu TS, Miranda WL, Moisés RS: Plasma adiponectin levels and incident glucose intolerance in Japanese-Brazilians: a seven-year follow-up study. Diabetes Res Clin Pract 2006, 73:304-309.

15. Matthews DR, Hosker JP, Rudenski AS, Naylor BA, Treacher DF, Turner RC: Homeostasis model assessment: insulin resistance and beta-cell function from fasting plasma glucose and insulin concentrations in man. Diabetologia 1985, 28:412-419.

16. Alberti KGMM, Zimmet PZ, for the World Health Organization Consultation: Definition, diagnosis and classification of diabetes mellitus and its complications. Part 1: Diagnosis and classification of diabetes mellitus. Report of a WHO Consultation. Geneva: WHO; 1999.

17. Pajvani UB, Du X, Combs TP, Berg AH, Rajala MW, Schulthess T, Engel Brownlee M, Scherer PE: Structure-function studies of the adipocytesecreted hormone Acrp30/adiponectin. Implications for the metabolic regulation and bioactivity. J Biol Chem 2003, 278:9073-9085.

18. Tsao TS, Murrey HE, Hug C, Lee DH, Lodish HF: Oligomerization statedependent activation of NF-KB signaling pathway by adipocyte complement-related protein of $30 \mathrm{kDa}$ (Acrp30). J Biol Chem 2002. 277:29359-29362

19. Schraw T, Wang ZV, Halberg N, Hawkins M, Scherer PE: Plasma adiponectin complexes have distinct biochemical characteristics. Endocrinology 2008, 149:2270-2282.

20. Vendramini MF, Pereira AC, Ferreira SR, Kasamatsu TS, Moisés R: JapaneseBrazilian Diabetes Study Group. Association of genetic variants in the adiponectin encoding gene (ADIPOQ) with type 2 diabetes in Japanese Brazilians. J Diabetes Complications 2010, 24:115-120.

21. Nakashima R, Kamei N, Yamane K, Nakanishi S, Nakashima A, Kohno N: Decreased total and high molecular weight adiponectin are independent risk factors for the development of type 2 diabetes in Japanese-Americans. J Clin Endocrinol Metab 2005, 91:3873-3877.

22. Retnakaram R, Connelly PW, Maguire G, Sermer M, Zinman B, Hanley AJ: Decreased high-molecular-weight adiponectin in gestational diabetes: implications for the pathophysiology of type 2 diabetes. Diabetes Med 2007, 24:245-252. 
23. Blüher M, Brennan AM, Kelesidis T, Kratzsch J, Fasshauer M, Kralisch $\mathrm{S}$, Williams CJ, Mantzoros CS: Total and high-molecular weight adiponectin in relation to metabolic variables at baseline and in response to an exercise treatment program. Diabetes Care 2007, 30:280-285.

24. Zhu N, Pankow JS, Ballantyne CM, Couper D, Hoogeveen RC, Pereira M, Duncan BB, Schmidt MI: High-molecular-weight adiponectin and the risk of type 2 diabetes in the ARIC study. J Clin Endocrinol Metab 2010, 95:5097-5104.

25. Schober F, Neumeier M, Weigert J, Wurm S, Wanninger J, Schaffer A, Dada A, Liebisch G, Schmitz G, Aslanidis C, Buechler C: Low molecular weight adiponectin negatively correlates with the waist circumference and monocytic IL-6 release. Biochem Biophys Res Commun 2007, 361:968-973.

26. Basu R, Pajvani UB, Rizza RA, Scherer PE: Selective downregulation of the high molecular weight form of adiponectin in hyperinsulinemia and type 2 diabetes: differential regulation from nondiabetic subjects. Diabetes 2007, 56:2174-2177.

doi:10.1186/1758-5996-5-20

Cite this article as: Crispim et al:: Adiponectin complexes composition in Japanese-Brazilians regarding their glucose tolerance status. Diabetology \& Metabolic Syndrome 2013 5:20.

\section{Submit your next manuscript to BioMed Central and take full advantage of:}

- Convenient online submission

- Thorough peer review

- No space constraints or color figure charges

- Immediate publication on acceptance

- Inclusion in PubMed, CAS, Scopus and Google Scholar

- Research which is freely available for redistribution 